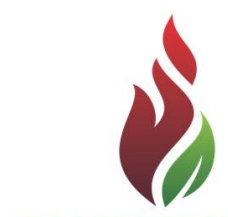

\section{ANÁLISE DO IMPACTO DAS FUSÕES E AQUISIÇÕES NA CRIAÇÃO DE VALOR E NO RETORNO DAS AÇÕES ORDINÁRIAS DOS PRINCIPAIS BANCOS BRASILEIROS DE GRANDE PORTE ENTRE 2003 A 2013}

\section{RESUMO}

As fusões e aquisições representam a possibilidade de criação de valor para o acionista. As decisões por tal porte de investimento têm diferentes motivações, muitas justificadas em teorias econômicas: da maximização dos lucros da firma e utilidade gerencial. A mensuração dos resultados das transações com F\&A's, em curto e longo prazo, foram pelo método do estudo de eventos e do EVA®, respectivamente. O segmento de indústria em análise foi de instituições financeiras, em especial, bancos, com ações negociadas na BOVESPA e ativos totais superiores a $\mathrm{R} \$ 500$ milhões. A especificidade e a preponderância do setor na economia brasileira demonstraram que o teste aplicado para 22 eventos de F\&A's, entre 2003-2013, apresentou retornos anormais estatisticamente não significativos em curto prazo, e que o desempenho em longo prazo, em sua maioria, medido pelo EVA $®$ geraram valor ao acionista.

PALAVRAS-CHAVES: Fusões e Aquisições; Bancos; Criação de Valor; Estudo de Eventos; EVA®.

\section{EXAMINATION OF THE IMPACT OF MERGERS AND ACQUISITIONS IN THE WEALTH CREATION AND VALUE AND RETURN OF THE COMMON SHARES OF THE MAIN LARGE BRAZILIAN BANKS BETWEEN 2003-2013}

\section{ABSTRACT}

Mergers and acquisitions represent the possibility of creating shareholder value. The decisions for such investment size have different motivations, many justified on economic theories: the maximization of profits of the firm and management utility. The measurement of results of transactions with M\&A's in short and long term, were by the event study method and EVA®, respectively. The industry segment analysis was financial institutions, especially banks, with shares traded on the BOVESPA and total assets in excess of $R \$ 500$ million. The specificity and the preponderance of the sector in the Brazilian economy demonstrated that the test applied to 22 M\&A's events, among 2003 through 2013, is statistically no significant abnormal returns in the short term and the long-term performance, mostly measured by EVA® generated shareholder value.

KEYWORDS: Mergers and Acquisitions; Banking; Value Creation; Event Study; EVA®.
Revista Brasileira de

Administração Científica, Aquidabã, v.6, n.1, Jan, Fev, Mar, Abr, Mai, Jun 2014.

ISSN 2179-684X

SECTION: Articles

TOPIC: Finanças e Contabilidade

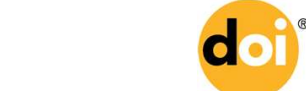

DOI: 10.6008/SPC2179-684X.2015.001.0008

Valeria Regina Bertoncelo

Pontifícia Universidade Católica de São Paulo, Brasil http://lattes.cnpq.br/6707683145906208

valrbertoncelo@hotmail.com

Jose Odalio dos Santos

Pontifícia Universidade Católica de São Paulo, Brasi http://lattes.cnpq.br/7018280423685826 jodalio569@gmail.com

Alexandre Franco de Godoi Centro Universitário Salesiano de São Paulo, Brasil http://lattes.cnpq.br/4704578926015219 godoifranco@hotmail.com

Received: 07/04/2015

Approved: 14/10/2015

Reviewed anonymously in the process of blind peer.

Referencing this:

BERTONCELO, V. R.; SANTOS, J. O.; GODOI, A. F. Análise do impacto das fusões e aquisições na criação de valor e no retorno das ações ordinárias dos principais bancos brasileiros de grande porte entre 2003 a 2013. Revista Brasileira de Administração Científica Aquidabã, v.6, n.1, p.133-150, 2015. DOI: http://dx.doi.org/10.6008/SPC2179$684 \times .2015 .001 .0008$ 


\section{INTRODUÇÃO}

Entre a década de 1950-1980, a política econômica do país foi voltada para a construção de uma potência mundial autossuficiente, o modelo nacionalista-desenvolvimentista, protecionista, com reservas de mercado e da existência de um número relevante de empresas estatais, mas também, da existência da concessão de incentivos para a expansão do setor produtivo privado. A partir de 1994, com o Plano Real, houve a primeira e significativa mudança. As metas de controle da economia hiper-inflacionária promoveriam alteração do modelo de gestão de negócios nas organizações. Neste período, as operações de F\&A foram preponderantes, devido à globalização de mercados reais; intensificação dos fluxos mundiais de investimentos estrangeiros diretos; redução de mecanismos tradicionais de proteção; remoção de barreiras ao ingresso de capitais estrangeiros, para investimentos diretos no país; privatizações; processo sucessório em empresas familiares e de fatores macroeconômicos, representados por crises internacionais - (1995) México, (1997) - Asiática, (2008) EUA - (ROSSETI, 2001).

A estabilidade promovida pelo plano Real trouxe o fim do chamado lucro inflacionário, provocando a reestruturação de diversos setores da economia, inclusive, o bancário. Muitas destas instituições tinham dependência significativa da geração de suas receitas em um ambiente inflacionário. Também, ficou evidente a ineficiência das instituições financeiras, trazendo à tona, a intensificação de programas de apoio à reestruturação do setor financeiro (PROER) e da redução da participação do setor público em atividade bancária (PROES).

O Programa de Estimulo à Reestruturação e ao Fortalecimento do Sistema Financeiro e Nacional (PROER) foi um instrumento necessário para impedir o colapso do sistema financeiro nacional e de seus desdobramentos na economia. Como resultado, oito fusões e aquisições foram realizados no âmbito do programa (Banco Nacional, Econômico, Bamerindus, Mercantil, Banorte, Pontual e Crefisul). Já, o PROES - programa de incentivo à redução do setor público - foi o refinanciamento dos estados brasileiros endividados, através da privatização dos bancos públicos estaduais.

Neste mesmo período, também, houve a remoção de barreiras de entrada ao capital estrangeiro em atividades bancárias, via exclusão da exigência do capital regulatório em dobro ao exigido dos bancos nacionais. Isto foi como um vetor de estímulo à eficiência operacional face a maior capacidade financeira dos bancos estrangeiros, com reflexos positivos sobre os custos dos serviços oferecidos ao público (PAULA et al., 2013). Ao longo destes 20 anos, as instituições financeiras, no Brasil, assim como em outras economias, se transformaram em grandes conglomerados diversificados e muitos deles, internacionalizados, devido à significância das transações com fusões e aquisições. Para Santomero (1999), a consolidação é decorrente da mudança das atividades dos bancos, passando de intermediários financeiros para serviços e assessoria financeira e comércio de risco. Para Dymski (1999), Berger e Berger et al. (1999, 2003), Group of Ten (2001), Amel et al. (2004), Jones e Critchfield (2005), Humphrey et al. (2006), 
tais mudanças foram provocadas pelas inovações tecnológicas, em especial, o advento da internet, que alterou significativamente a eficiência dos fatores de produção do setor, ou $X$ efficiency. Uma das estratégias adotadas para a obtenção da eficiência operacional foram as fusões e aquisições voltadas para economias em escala e escopo.

Em exame das divulgações de fato relevante registradas no BACEN e na BOVESPA, pelos principais bancos brasileiros, entre 2003 a 2013, observa-se que as justificativas são, em sua maioria, devido à necessidade de expansão territorial e da carteira, diversificação de produtos e serviços e de aumento de tamanho, corroborando com a abordagem das pesquisas. $O$ presente trabalho tem por objetivo analisar o impacto da das decisões relevantes de investimento, em especial fusões e aquisições de instituições financeiras, em curto e longo prazo. O método de análise em curto prazo é da aplicação de estudo de eventos, com aplicação do modelo de retornos ajustados ao mercado; e para fins de análise em longo prazo, é da utilização da medida de desempenho $E V A^{\circledR}$ - Economic Value Added. Espera-se que o trabalho contribua para maior conhecimento sobre o desempenho dos principais bancos brasileiros mediante as decisões de investimento e também, do comportamento do mercado acionário brasileiro.

\section{REVISÃO TEÓRICA}

\section{Fundamentação, Hipóteses e Motivações das transações com Fusões e Aquisições}

As fusões e aquisições são decisões de investimento em longo prazo, portanto, requerem de seus administradores a adequada alocação dos recursos disponíveis para fins de maximização da riqueza dos seus acionistas, como corrobora a Teoria Neoclássica da Maximização dos Lucros da Firma. A geração de riqueza e valor é decorrente da melhoria do desempenho da empresa adquirente através das hipóteses de sinergia, criação de poder e controle e ou da injeção de uma administração profissionalizada na empresa adquirida. Portanto, é esperado que a decisão estratégica de investimento, com a aplicação dos recursos da empresa em projetos rentáveis, reflita no valor das ações de uma empresa, quando da sua divulgação, em hipótese de mercado eficiente (ASSAF NETO, 2012).

Por outro lado, é possível que a existência de conflitos na execução dos objetivos de maximização da riqueza dos acionistas em detrimento do interesse próprio dos seus gestores, levem às decisões de investimento pouco agregadoras de valor à firma. É a denominada Teoria da Maximização da Utilidade Gerencial. Estas teorias, oriundas da microeconomia, orientam grande parte dos estudos da administração, porque se baseiam na afirmação de que a ação humana é subordinada à razão, portanto, as ações são racionais e logram objetivos definidos. Mas, é importante ressaltar que diversos estudos apontaram a existência de anomalias não totalmente explicadas pela corrente neoclássica, surgindo um paradigma alternativo, denominado 
de finanças comportamentais, cuja base foram os estudos de Kahneman e Tversky (1981), na teoria da perspectiva.

Neste novo contexto, admite-se que os indivíduos e ou investidores cometam erros sistemáticos, quer seja na forma de processamento das informações disponíveis, no excesso de confiança e que produzem decisões inconsistentes ou subótimas, mesmo dada à distribuição de probabilidade de retorno (DANIEL \& TITMAN, 1999). As teorias econômicas e os estudos de finanças comportamentais são utilizados nas pesquisas, para a identificação das hipóteses e ou motivações dos administradores em decisões de investimento de relevância para a firma. Entre as hipóteses frequentemente pesquisadas, destacam-se a busca pela: eficiência ( $X$-Efficiency) ou da sinergia operacional, financeira e de gestão; necessidade de crescimento, expansão de mercados; da proteção dos efeitos anticompetitivos e da busca do poder de mercado; do excesso de autoconfiança dos gestores - Hubris Hipothesys e dos problemas de agência.

Para o segmento de bancos, associado ao período em análise, ressalta-se, a busca pela eficiência, face à alteração do padrão devido ao advento da internet e também, pela busca da expansão geográfica e diversificação de produtos e serviços. Portanto, é esperado que os movimentos de fusão e aquisição demonstram corroborem com desempenho superior, oriundo da economia em escala e de escopo; da redução dos custos transacionais, melhoria da estrutura de capital e da eliminação da ineficiência administração ou de gestão (BERGER et al.; 1999).

\section{Riscos, Métricas de Gestão das Instituições Financeiras}

As Instituições Financeiras apresentam características específicas em relação às empresas de segmentos não financeiros, e seu objeto social está relacionado à intermediação financeira. A captação e os empréstimos de recursos são as suas atividades operacionais preponderantes, associados aos riscos inerentes à sua atividade, consequentemente, dos níveis de alavancagem financeira de suas operações. Estes riscos afetam, de forma contínua, os processos decisórios de seus administradores e suas estratégias relativas à gestão de risco. A eficácia desta gestão se torna essencial para o seu desempenho (SAUNDERS, 2000).

Neste contexto, o Banco Central do Brasil (BACEN) que é o órgão responsável pelo processo de supervisão e regulação das instituições financeiras, também, tem por objetivo, assegurar a solidez do Sistema Financeiro Nacional (SFN). Este constante monitoramento diz respeito à capacidade da administração de cada instituição financeira, em gerir os riscos de riscos de crédito, de mercado, operacional tecnológico, cambio, de liquidez, soberano, insolvência e operações fora do balanço, além da garantia um capital regulatório mínimo.

Em especial ao risco de liquidez, em 1988, dez maiores bancos centrais do mundo, assinaram o primeiro acordo da Basiléia com o objetivo de adequação do capital dos bancos para que minimizasse os riscos de insolvência das instituições financeiras, além da melhoria da estabilidade do sistema financeiro internacional. Este acordo sugeriu a manutenção de um capital 
próprio mínimo para as instituições financeiras, equivalentes a $8 \%$ do ativo ponderado pelo risco. No Brasil, o acordo da Basiléia I foi implementado através da Resolução nº 2.099, onde introduziu o requerimento da exigência de capital mínimo em $11 \%$.

Com o passar dos anos, as regras adotadas no acordo da Basiléia I, não se mostraram suficientes para minimização riscos da atividade de intermediação e o Comitê decidiu pela revisão e estruturação do acordo da Basileia II em 3 pilares: requerimentos de capital adequado e proporcional aos riscos operacionais, de crédito e de mercado, processo de revisão por parte de equipe responsável pela supervisão bancária de adequação do capital mínimo das instituições e disciplina de mercado que é relativa a necessidade de políticas de governança corporativa, garantindo a transparência e controles de riscos das atividades de intermediação financeira.

Em 2008-2009, as fragilidades relativas a cadeia de originação de crédito, capitalização indevida e da falta de transparência levaram à crise financeira internacional, demonstrando que as instituições financeiras não tinham liquidez suficiente para absorver eventuais choques. Isto levou a reformulação das regras do Acordo da Basiléia II. Surge, então, o Basileia III, propondo: reformulação da estrutura de capital das instituições financeiras, através do aprimoramento do cálculo do ativo ponderado pelo risco, da ampliação dos requerimentos de capital e redefinição do capital regulamentar em nível I e II; introdução dos índices de liquidez para que a instituição financeira tenha ativos suficientes para liquidação, sem perda relevante de valor em situações de estresse de mercado; introdução índice de alavancagem para limitar exposição a graus de fragilidade financeira muito elevados.

O capital regulatório é uma especificidade do segmento financeiro, representam reservas disponíveis, não atrelados a nenhuma operação comercial, portanto, suficientes para absorver os riscos da operação de intermediação financeira e de eventuais choques (ELIOTT, 2010). Por isto, o conceito de capital mínimo regulatório é de extrema importância para os bancos, pois quanto maior a exposição, maior a necessidade de capital. O acordo da Basiléia traz para fins de gerenciamento do capital bancário, o denominado índice da Basiléia, que é a relação entre o Patrimônio de Referência (PR) e o Patrimônio de Referência Exigido (PRE).

O Patrimônio de Referência é a medida de capital utilizada pelos órgãos reguladores para a verificação dos limites operacionais das instituições financeiras. De acordo com a Basiléia são classificados em: nível I ou o capital primário, incluí o capital social e suas reservas, lucros e lucros acumulados e deduções de ágio; nível Il ou de recursos secundários de capital, incluindo as reservas de reavaliação, ajustes de marcação a mercado de títulos, valores mobiliários e derivativos, outros instrumentos híbridos de capital e de dívida subordinada.

O capital nível I se aproxima do patrimônio líquido contábil das instituições financeiras (SAUNDERS, 2000). Já o capital de nível II, em especial os instrumentos híbridos de capital e de dívida subordinada, é decorrente do conceito de recursos que não tem obrigatoriedade de pagamento imediato; prazos longos; não requerem pagamentos de dividendos e de juros e em casos de concordata e ou liquidação, não tem prioridade de imediata de pagamento, portanto, 
passíveis de utilização em curto prazo, para absorção de choques e outros riscos. É considerada uma forma soft de capital e permite aos acionistas a utilização de recurso economicamente mais barato, se comparado com o custo de capital próprio. Caso contrário, seria necessário o aporte dos acionistas ou a revisão dos limites de operação da instituição financeira.

O Patrimônio Referência Exigido (PRE) é o patrimônio exigido da instituição decorrente da ponderação do grau de risco das operações ativas, ou seja, do capital em risco, consequentemente diferente do Patrimônio Líquido (BASTOS, 1999). O PRE é calculado, a partir, da soma das parcelas de patrimônio exigido para a cobertura das exposições aos diversos riscos, conforme a seguinte fórmula:

PRE: $\quad$ PEPR + $\quad+$ PCAM+PJUR+PCOM+PACS + POPR + AdicBC
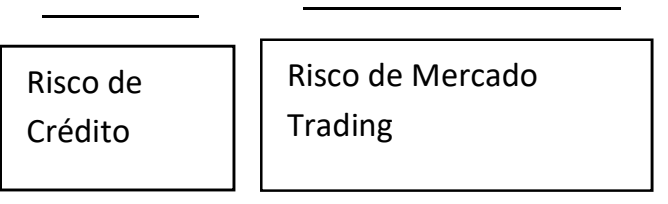

Onde:

PEPR: exposições ponderadas pelo nível de risco atribuído

P СAM: exposições em ouro, moeda estrangeira e em operações sujeitas à variação cambial.

PJuR: operações sujeitas à variação de juros.

Pсом: operações sujeitas à variação do preço das mercadorias - commodities.

$P_{\text {Acs: }}$ operações sujeitas à variação do preço de ações.

PopR: patrimônio exigido para cobertura do risco operacional.

AdicBC: é o aumento do valor do PRE da instituição que o Banco do Brasil poderá determinar eventualmente.

Neste trabalho, o patrimônio de referência divulgados pelas instituições financeiras será base de remuneração do capital próprio e os ativos ponderados ao risco (APR), a eficiência operacional (IEO), os lucros serão analisados em conjunto com a métrica de desempenho econômico-financeiro: $E V A^{\circledR}$ que representará o conceito de rentabilidade.

\section{METODOLOGIA}

As atividades de fusões e aquisições trazem para o âmbito da pesquisa, à avaliação recorrente da geração de valor para os acionistas. A mensuração da criação de valor, pode ser realizada da seguinte forma: Em curto prazo - Através do método de estudo de eventos, é possível avaliar os impactos nos preços das ações em face das divulgações relativas a transações de fusões e aquisições, da distribuição de dividendos, estruturação de dívidas e até de variáveis macroeconômicas. Este método de pesquisa tem como base a hipótese de mercado eficiente, onde há um expressivo número de participantes racionais, competidores e à busca de 
maximização dos lucros. Neste contexto os participantes tentam previr o valor individual dos ativos, com base nas informações disponíveis e sem custo. Portanto, o preço do ativo será, em qualquer momento, a melhor estimativa de seu valor intrínseco (FAMA, 1991). De acordo com Campbell et al. (1997), o estudo de eventos permite mensuração do efeito de um evento econômico no valor de uma empresa. Assim, para um ativo (i) data do evento ${ }_{(\mathrm{t})}$, o retorno anormal (RA) é:

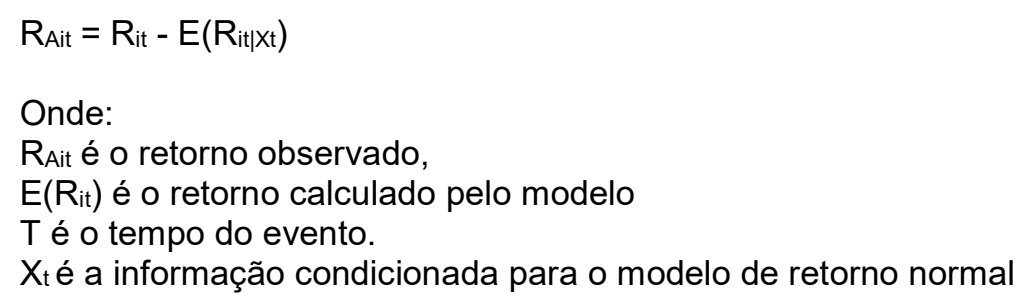

O retorno esperado do ativo, no presente trabalho, é calculado com base no modelo de mercado que são considerados como modelo de um fator, no caso, o retorno da carteira de mercado IBOVESPA. Assim, o modelo de mercado pode ser assim expresso:

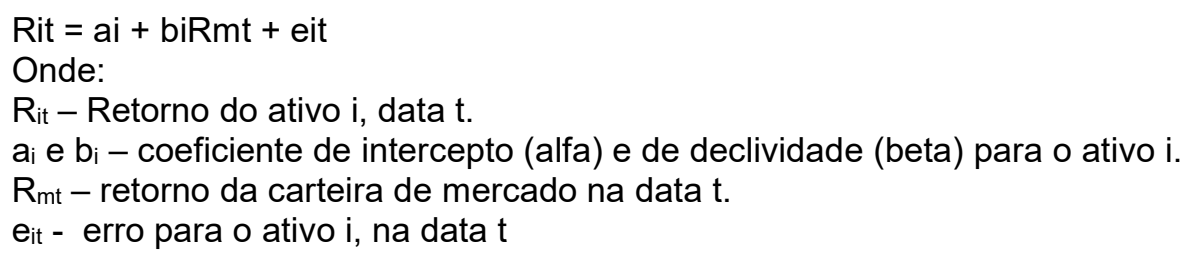

O retorno anormal é realizado a partir de três parâmetros: data do evento - data de divulgação do evento; janela de estimação - período anterior a divulgação utilizado para calcular o intercepto alfa e o coeficiente beta; e janela do evento período em que se calcula o retorno anormal que é diferença entre o retorno efetivo e o retorno esperado. Finalmente, os retornos anormais são acumulados - cumulative abnormal return (CAR) - entre o primeiro e último dia da janela de evento, conforme expresso abaixo:

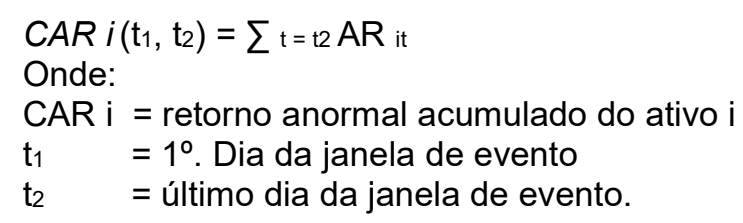

(b) Em longo prazo: A medida de desempenho: EVA ${ }^{\circledR}$ mensura em um determinado período quanto à empresa agregou de riqueza aos seus acionistas em relação ao um custo de oportunidade do mercado. Adoção do $E A^{\circledR}$ foi a partir da década de 80, como uma medida de desempenho financeiro de utilização interna e de divulgação externa. As suas bases conceituais são da microeconomia, que estabelecia a correlação entre os lucros auferidos e a criação de valor (BELL, 1998). Para Alfred Marshall (1920), o lucro contábil auferido deveria ser ajustado ao custo 
de oportunidade do capital, uma vez que medida: lucro, não ajustada, representaria um indicador enganoso de desempenho para fins de ordem prática e teórica.

Solomons (1965) operacionalizou uma medida de criação de riqueza denominada de lucro econômico, pois eram deduzidos dos lucros após os impostos, o custo do capital investido, remanescendo o lucro residual. Biddle et al. (1997) denominam de retornos anormais, ganhos excedentes etc. As formas de cálculo para a determinação do $E A^{\circledR}$ são duas, como demonstradas abaixo, entretanto, há uma terceira, ajustada para instituições financeiras em face das especificidades do segmento e da dificuldade na determinação do custo médio de capital (ASSAF NETO, 2012).

As fontes de financiamento dos bancos são oriundas de depósitos à vista, de linhas de crédito de outras instituições e agências governamentais, com prazos e taxas diferentes (BASTOS, 1999). Por tratar-se da própria atividade dos bancos, isto, ocasiona certa dificuldade em determinar o custo médio ponderado de capital, além das restrições legais impostas aos passivos contraídos pela instituição.

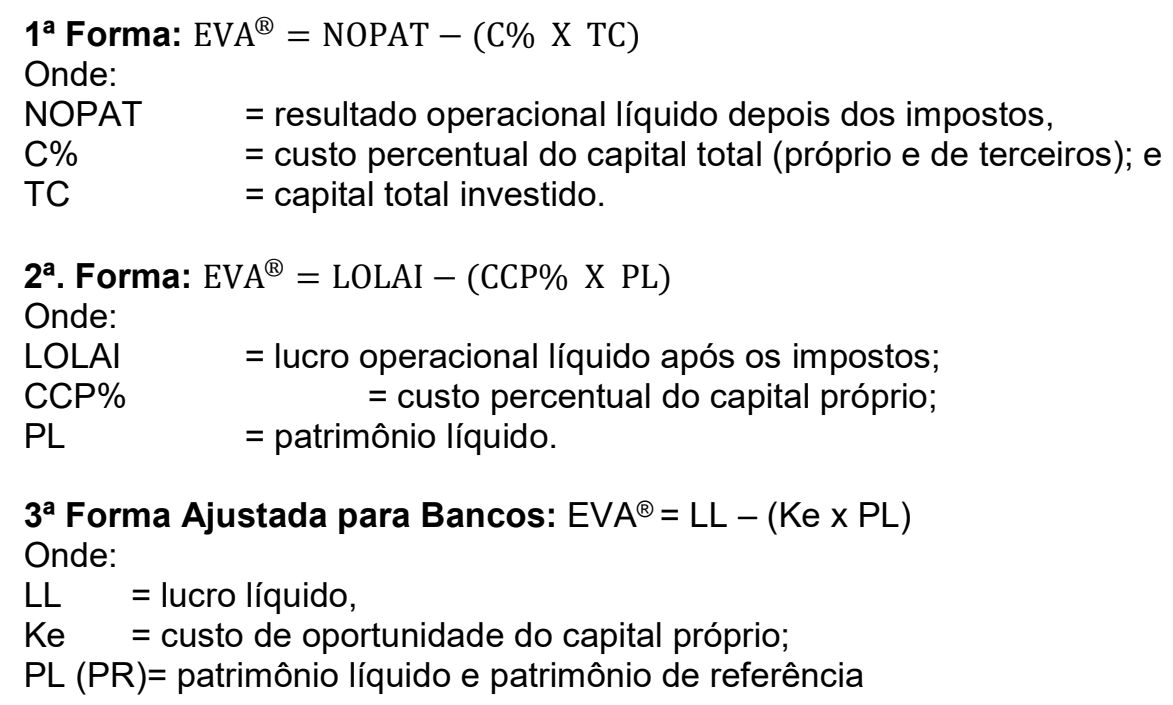

A proposta de Assaf Neto (2012) é uma derivação da $2^{a}$ forma, onde o lucro operacional líquido após os impostos (LOLAl) inclui as despesas financeiras, portanto, é o lucro líquido (LL), exceto por eventuais impactos de resultados não operacionais, em sua maioria, representados por alienações de investimentos e seus custos associados. No presente trabalho, adota-se o modelo proposto por Assaf Neto (2012), com a substituição do PL pelo PR - patrimônio de referência e da remuneração pela taxa SELIC. A utilização do PR reflete a transição do Basiléia III, onde os bancos devem aumentar a participação do capital nível I com isto, eventuais impactos na geração de valor. Para Jokipii e Milne (2011), os requerimentos de capital estão entre os principais instrumentos da regulação bancária ao prevenir os bancos de tomarem riscos excessivos, e também ao proporcionar maior segurança ao sistema financeiro em momentos adversos da economia.

\section{Amostra}


No presente artigo, os eventos analisados são das F\&A's ocorridas entre janeiro de 2003 a dezembro de 2013, de instituições financeiras, em especial bancos nacionais, com ações negociadas no BOVESPA e ativos totais superiores a $\mathrm{R} \$ 500$ milhões. $\mathrm{O}$ tratamento dos dados resultou em uma amostra de 3 principais bancos: Banco do Brasil, Itaú-Unibanco, Bradesco que entre 2003 a 2013, atuaram em 22 transações de F\&A's, onde a predominância do porte foi de 40 \% em médio ( $\mathrm{R} \$ 201$ milhões-R $\$ 1,9$ bilhões) e grande (acima de $\mathrm{R} \$ 2$ bilhões), como destacados no quadro 1.

Quadro 1: Amostra de F\&A's Bancos adquirentes.

\begin{tabular}{|c|c|c|c|c|}
\hline $\begin{array}{l}\text { Banco } \\
\text { Adquirente }\end{array}$ & $\begin{array}{l}\text { Data de } \\
\text { Divulgação }\end{array}$ & Ativo & Meios de Pagamento & $\begin{array}{l}\text { Valor da } \\
\text { Transação }\end{array}$ \\
\hline \multirow[t]{4}{*}{ Bradesco } & 22.05 .2003 & Banco Bilbao Vizcaya & Emissão de Ações & $\mathrm{R} \$ 2,6$ milhões \\
\hline & 07.11 .2003 & Banco Zogbi & Disponibilidades & $\mathrm{R} \$ 650$ milhões \\
\hline & 11.02 .2004 & $\begin{array}{l}\text { BEM - Banco Estado do } \\
\text { Maranhão. }\end{array}$ & Disponibilidades & R\$78 milhões \\
\hline & 21.12 .2005 & $\begin{array}{l}\text { BEC - Banco do Estado } \\
\text { do Ceará. }\end{array}$ & Disponibilidades & $\mathrm{R} \$ 700$ milhões \\
\hline \multirow[t]{3}{*}{ Bradesco } & 28.06 .2006 & Amex do Brasil & Disponibilidades & $\mathrm{R} \$ 1$ bilhão \\
\hline & 24.01 .2007 & Banco BMC & Emissão de Ações & $\mathrm{R} \$ 800$ milhões \\
\hline & 04.06 .2009 & Banco Ibi & Emissão de Ações & $\mathrm{R} \$ 1,3$ bilhões \\
\hline \multirow[t]{7}{*}{ Banco do Brasil } & 11.09.2008 & $\begin{array}{l}\text { Banco do Estado de } \\
\text { Santa Catarina }\end{array}$ & Emissão de Ações & $\mathrm{R} \$ 682$ milhões \\
\hline & 20.11 .2008 & $\begin{array}{l}\text { Nossa Caixa Nosso } \\
\text { Banco }\end{array}$ & Disponibilidades & $\mathrm{R} \$ 5,4$ bilhões \\
\hline & 28.11 .2008 & Banco do Estado do Piauí & Emissão de Ações & $\mathrm{R} \$ 81,7$ milhões \\
\hline & 28.09 .2009 & Banco Votorantim & $\begin{array}{l}\text { Emissão de Ações e } \\
\text { Disponibilidades }\end{array}$ & $\mathrm{R} \$ 4,2$ bilhões \\
\hline & 15.10 .2009 & IRB & Disponibilidades & $\mathrm{R} \$ 547$ milhões \\
\hline & 21.04 .2010 & Banco da Patagônia & Disponibilidades & US480 milhões \\
\hline & 25.04 .2011 & Eurobank & Disponibilidades & US6 milhões \\
\hline
\end{tabular}

\begin{tabular}{|l|l|l|l|l|}
\hline $\begin{array}{l}\text { Banco } \\
\text { Adquirente }\end{array}$ & $\begin{array}{l}\text { Data de } \\
\text { Divulgação }\end{array}$ & Ativo & Meios de Pagamento & $\begin{array}{l}\text { Valor da } \\
\text { Transação }\end{array}$ \\
\hline \multirow{4}{*}{ Itaú-Unibanco } & 27.03 .2003 & Banco Fiat & Disponibilidades & $\mathrm{R} \$ 897$ milhões \\
\cline { 2 - 5 } & 20.10 .2003 & AGF Seguros & Disponibilidades & $\mathrm{R} \$ 243$ milhões \\
\cline { 2 - 5 } & 02.05 .2006 & Bank Boston Brasil, Chile e & Emissão de Ações & $\mathrm{R} \$ 4,5$ bilhões \\
& 08.08 .2006 & Uruguai & Emissão de Ações & $\mathrm{R} \$ 104$ bilhões \\
\cline { 2 - 5 } & 03.11 .2008 & Unibanco & Disponibilidades & $\mathrm{R} \$ 85$ milhões \\
\cline { 2 - 5 } & 10.07 .2012 & Banco BMG & Disponibilidades & $\mathrm{R} \$ 2,9$ bilhões \\
\cline { 2 - 5 } & 14.05 .2013 & Credicard & & \\
\hline
\end{tabular}

\section{RESULTADOS}

\section{Resultados em Curto Prazo - Estudo de Eventos}

Em contribuição com os demais estudos realizados por Dymski (1999), Berger e Berger et al. (1999, 2003), DeLong (2001), Group of Ten (2001), Amel et al. (2004), Brewer et al. (2000), Penas e Unal (2004), Henock (2004), Brito et al. (2004), Olson e Pagano (2005), Jones e Critchfield (2005), DeLong e DeYoung (2005) e Humphrey et al (2006), a presente pesquisa analisou 22 aquisições, entre 2003 a 2013, realizadas por bancos nacionais, com ações negociáveis na BOVESPA, resultou em retornos anormais acumulados com pouca variância 
entorno das janelas de eventos, corroborando com os resultados obtidos na pesquisa de Jensen e Ruback (1983).

A pesquisa utilizou onze janelas de eventos, incluindo a data do evento, dias posteriores e anteriores ao anúncio, conforme demonstrado no quadro 2. O principal objetivo da utilização de janelas posteriores é em decorrência do tempo necessário para o mercado se ajustar às divulgações e as janelas anteriores é certificação de eventual antecipação do mercado em relação ao anúncio do evento, como consequência, alteração do preço das ações.

Quadro 2: Janela de eventos.

\begin{tabular}{|l|l|l|}
\hline \multirow{4}{*}{ Janela } & $(5 ; 0)$ & Dia do evento e cinco pregões anteriores \\
\cline { 2 - 3 } & $(4 ; 0)$ & Dia do evento e quatro pregões anteriores \\
\hline$(3 ; 0)$ & Dia do evento e três pregões anteriores \\
\hline & $(2 ; 0)$ & Dia do evento e dois pregões anteriores \\
\cline { 2 - 3 } & $(1 ; 0)$ & Dia do evento e um pregão anterior \\
\cline { 2 - 3 } & $(0 ; 0)$ & Dia do evento \\
\hline & $(0 ; 1)$ & Dia do evento e um pregão posterior \\
\hline & $(0 ; 2)$ & Dia do evento e dois pregões posterior \\
\hline & $(0 ; 3)$ & Dia do evento e três pregões posterior \\
\hline & $(0 ; 4)$ & Dia do evento e quatro pregões posterior \\
\cline { 2 - 3 } & $(0 ; 5)$ & Dia do evento e cinco pregões posterior \\
\hline
\end{tabular}

O quadro 3 apresenta os retornos anormais acumulados por banco e seus ativos com as respectivas janelas de evento $(-6 ;+6)$. O resultado não demonstra variações percentuais superiores ao intervalo $-4 ;+4 \%$, nas respectivas janelas de eventos, inferindo à agregação anormal dos preços dos ativos decorrente da divulgação das F\&A's, exceto quanto à janela $(0,0)$ para a divulgação das aquisições: BMC (-5,21\%); AMEX (-4,73\%), Unibanco (10,26\%), (6,06\%).

Em 2008, a crise internacional reduziu a liquidez do Sistema Financeiro Internacional, consequentemente, da disponibilidade das linhas de crédito, principalmente para indústrias de capital intensivo. Para os bancos privados brasileiros, listados na BOVESPA, é observado ajuste dos preços das ações, demonstrando uma tendência de redução dos preços dos ativos, face ao cenário de incerteza e da extensão dos impactos à indústria. Cenário propício para F\&A`s. Neste período as aquisições, realizadas pelo Banco do Brasil, não foram suficientes, na percepção do mercado para conter eventuais ajustes dos preços, mas a variação dos retornos, na janela $(0 ; 0)$ foram de $-1,45 \%$ a $1,25 \%$, mas, não necessariamente significativos quando comparados com redução do preço dos papéis face à crise. Outro fator preponderante aos retornos registrados é o alvo da aquisição: bancos públicos que historicamente, apresentam necessidades de investimento de integração das plataformas de negócios. Em movimento contrário aos resultados registrados do BB, o Banco Itaú com a fusão no Unibanco, na janela $(0 ; 0)$ registrou retornos acumulados em $10,8 \%$.

Ao longo destes dez anos os retornos anormais analisada entorno da divulgação de investimentos em F\&A's são relativamente estáveis, exceto quanto os casos acima mencionados, mas estatisticamente não significativos dado um nível de confiança de $10 \%$, conforme demonstrado no quadro 4, abaixo. 
Quadro 3: Retorno Anormal Acumulado por Janela.

\begin{tabular}{|c|c|c|c|c|c|c|c|c|c|c|c|c|c|}
\hline & Ano & $\begin{array}{l}\text { Ativo } \\
\text { Adquirido }\end{array}$ & $5 ; 0)$ & $4 ; 0)$ & $3 ; 0)$ & $2 ; 0)$ & $1 ; 0)$ & $0 ; 0)$ & $0 ; 1)$ & $0 ; 2)$ & $0 ; 3)$ & $0 ; 4)$ & $0 ; 5)$ \\
\hline \multirow{7}{*}{ BB } & 2008 & BESC & & & & & & & & & & & \\
\hline & 2008 & NCNB & & & & & & & & & & & \\
\hline & 2008 & BEP & & & & & & & & & & & \\
\hline & 2009 & VotoRTIM & & & & & & & & & & & \\
\hline & 2009 & IRB & & & & & & & & & & & \\
\hline & 2010 & Patagônia & & & & & & & & & & & \\
\hline & 2011 & Eurobank & & & & & & & & & & & \\
\hline \multirow{7}{*}{ BRA } & 2003 & BBV & & & & & & & & & & & \\
\hline & 2003 & Zogbi & & & & & & & & & & & \\
\hline & 2004 & BEM & & & & & & & & & & & \\
\hline & 2005 & BEC & & & & & & & & & & & \\
\hline & 2006 & AMEX & & & & & & & & & & & \\
\hline & 2007 & BMC & & & & & & & & & & & \\
\hline & 2009 & Banco lbi & & & & & & & & & & & \\
\hline \multirow{7}{*}{ Itaú } & 2003 & Banco Fiat & & & & & & & & & & & \\
\hline & 2003 & AGF & & & & & & & & & & & \\
\hline & 2003 & BKB Brasil & & & & & & & & & & & \\
\hline & 2006 & $\mathrm{BKB} \mathrm{U} / \mathrm{CH}$ & & & & & & & & & & & \\
\hline & 2008 & Unibanco & & & & & & & & & & & \\
\hline & 2012 & BMG & & & & & & & & & & & \\
\hline & 2012 & Credicard & & & & & & & & & & & \\
\hline
\end{tabular}

Os resultados observados nesta pesquisa podem ser justificados, em parte, pelo seguinte: Ausência de economias em escala para bancos de grande porte, mas muito presente em bancos de menor porte. Por outro lado a diversificação exige especialização e recursos para posterior busca por escala; Eventual não captura do X-efficiency - eficiência técnica, ou seja, eficácia da utilização dos recursos disponíveis tem maior importância a que economias de escala e de escopo. É a capacidade de gestão dos custos dos bancos, consequentemente de geração de resultados; Ondas de consolidação de segmentos de negócio antecipam os efeitos das aquisições, fusões, como consequência, não se observa ganhos anormais entorno do anúncio; $A$ eventual divulgação de um programa intensivo de aquisições pode antecipar em parte os efeitos das transações de F\&A`s, por isto, os efeitos entorno do anúncio podem não ter significância estatística; A existência de agentes regulatórios, leis de proteção ao investidor contribuem para uma crescente regulação das transações com F\&A's, inibindo, de certa forma as expectativas dos investidores por retornos anormais.

Quadro 4: $P$-value por Janela

\begin{tabular}{|l|l|l|l|l|l|l|l|l|l|l|l|l|}
\hline & $\begin{array}{l}\text { Ativo } \\
\text { Adquirido }\end{array}$ & $\mathbf{( 5 ; 0 )}$ & $\mathbf{( 4 ; 0 )}$ & $\mathbf{( 3 ; 0 )}$ & $\mathbf{( 2 ; 0 )}$ & $\mathbf{( 1 ; 0 )}$ & $\mathbf{( 0 ; 0 )}$ & $\mathbf{( 0 ; 1 )}$ & $\mathbf{( 0 ; 2 )}$ & $\mathbf{( 0 ; 3 )}$ & $\mathbf{( 0 ; 4 )}$ & $\mathbf{( 0 ; 5 )}$ \\
\hline BB & BESC & $\begin{array}{l}0,1979 \\
1\end{array}$ & $\begin{array}{l}0,3711 \\
\mathbf{9}\end{array}$ & $\begin{array}{l}0,3534 \\
\mathbf{2}\end{array}$ & $\begin{array}{l}0,1257 \\
\mathbf{4}\end{array}$ & $\begin{array}{l}0,1308 \\
5\end{array}$ & $\begin{array}{l}0,2865 \\
0\end{array}$ & $\begin{array}{l}0,5310 \\
\mathbf{4}\end{array}$ & $\begin{array}{l}0,5118 \\
0\end{array}$ & $\begin{array}{l}0,2502 \\
6\end{array}$ & $\begin{array}{l}0,3043 \\
7\end{array}$ & $\begin{array}{l}0,3704 \\
2\end{array}$ \\
\hline
\end{tabular}




\begin{tabular}{|c|c|c|c|c|c|c|c|c|c|c|c|c|}
\hline & NCNB & 4935 & $\begin{array}{l}0,4968 \\
9\end{array}$ & $\mid \begin{array}{l}0,4972 \\
5\end{array}$ & $\begin{array}{l}0,4987 \\
8\end{array}$ & $\begin{array}{l}0,4981 \\
5\end{array}$ & $\mid \begin{array}{l}0,4994 \\
6\end{array}$ & $\begin{array}{l}0,4959 \\
5\end{array}$ & $\begin{array}{l}0,4977 \\
9\end{array}$ & $\begin{array}{l}0,4974 \\
2\end{array}$ & $\begin{array}{l}0,4985 \\
3\end{array}$ & $\begin{array}{l}0,4982 \\
9\end{array}$ \\
\hline & BEP & $\begin{array}{l}0,4951 \\
3\end{array}$ & $\begin{array}{l}0,4964 \\
7\end{array}$ & $\begin{array}{l}0,4972 \\
4\end{array}$ & $\begin{array}{l}0,4975 \\
8\end{array}$ & $\begin{array}{l}0,4978 \\
7\end{array}$ & $\begin{array}{l}0,4980 \\
4\end{array}$ & $\begin{array}{l}0,4981 \\
7\end{array}$ & $\begin{array}{l}0,4983 \\
1\end{array}$ & $\begin{array}{l}0,4984 \\
0\end{array}$ & $\begin{array}{l}0,4984 \\
8\end{array}$ & $\begin{array}{l}0,4985 \\
5\end{array}$ \\
\hline & Votorantim & $\begin{array}{l}0,4461 \\
1\end{array}$ & $\begin{array}{l}0,4617 \\
4\end{array}$ & \begin{tabular}{|l}
0,4679 \\
0
\end{tabular} & \begin{tabular}{|l}
0,4728 \\
7
\end{tabular} & $\begin{array}{l}0,4759 \\
6\end{array}$ & $\begin{array}{l}0,4777 \\
4\end{array}$ & $\begin{array}{l}0,4796 \\
3\end{array}$ & \begin{tabular}{|l}
0,4809 \\
7
\end{tabular} & \begin{tabular}{|l}
0,4813 \\
7
\end{tabular} & $\begin{array}{l}0,4829 \\
0\end{array}$ & $\begin{array}{l}0,4834 \\
2\end{array}$ \\
\hline & IRB & $\begin{array}{l}0,4980 \\
5\end{array}$ & \begin{tabular}{|l}
0,4986 \\
0
\end{tabular} & $\begin{array}{l}0,4988 \\
8\end{array}$ & $\begin{array}{l}0,4990 \\
3\end{array}$ & $\begin{array}{l}0,4991 \\
0\end{array}$ & $\begin{array}{l}0,4992 \\
1\end{array}$ & $\begin{array}{l}0,4992 \\
6\end{array}$ & $\begin{array}{l}0,4993 \\
1\end{array}$ & $\begin{array}{l}0,4992 \\
8\end{array}$ & $\begin{array}{l}0,4993 \\
9\end{array}$ & $\begin{array}{l}0,4994 \\
2\end{array}$ \\
\hline & Patagônia & $\begin{array}{l}0,4977 \\
0\end{array}$ & $\begin{array}{l}0,4983 \\
6\end{array}$ & $\begin{array}{l}0,4986 \\
4\end{array}$ & $\begin{array}{l}0,4988 \\
5\end{array}$ & $\begin{array}{l}0,4989 \\
7\end{array}$ & $\begin{array}{l}0,4990 \\
6\end{array}$ & $\begin{array}{l}0,4991 \\
3\end{array}$ & $\begin{array}{l}0,4991 \\
8\end{array}$ & $\begin{array}{l}0,4991 \\
4\end{array}$ & $\begin{array}{l}0,4992 \\
8\end{array}$ & $\begin{array}{l}0,4992 \\
8\end{array}$ \\
\hline & Eurobank & $\begin{array}{l}0,4981 \\
1\end{array}$ & \begin{tabular}{|l}
0,4986 \\
6
\end{tabular} & \begin{tabular}{|l|l}
0,4988 \\
7
\end{tabular} & $\begin{array}{l}0,4990 \\
4\end{array}$ & $\begin{array}{l}0,4991 \\
4\end{array}$ & \begin{tabular}{|l}
0,4992 \\
3
\end{tabular} & \begin{tabular}{|l}
0,4992 \\
9
\end{tabular} & \begin{tabular}{|l}
0,4993 \\
2
\end{tabular} & \begin{tabular}{|l}
0,4993 \\
7
\end{tabular} & $\begin{array}{l}0,4994 \\
0\end{array}$ & $\begin{array}{l}0,4994 \\
3\end{array}$ \\
\hline & BBV & $\begin{array}{l}0,4968 \\
1\end{array}$ & $\begin{array}{l}0,4978 \\
2\end{array}$ & $\begin{array}{l}0,4980 \\
7\end{array}$ & $\begin{array}{l}0,4984 \\
7\end{array}$ & $\begin{array}{l}0,4986 \\
0\end{array}$ & $\begin{array}{l}0,4987 \\
5\end{array}$ & $\begin{array}{l}0,4988 \\
4\end{array}$ & $\begin{array}{l}0,4988 \\
7\end{array}$ & $\begin{array}{l}0,4989 \\
4\end{array}$ & $\begin{array}{l}0,4990 \\
3\end{array}$ & $\begin{array}{l}0,4990 \\
7\end{array}$ \\
\hline & Zogbi & $\begin{array}{l}0,4973 \\
9 \\
\end{array}$ & \begin{tabular}{|l}
0,4982 \\
2 \\
\end{tabular} & \begin{tabular}{|l}
0,4985 \\
1 \\
\end{tabular} & \begin{tabular}{|l}
0,4987 \\
3 \\
\end{tabular} & \begin{tabular}{|l}
0,4988 \\
7 \\
\end{tabular} & \begin{tabular}{|l}
0,4989 \\
6 \\
\end{tabular} & \begin{tabular}{|l}
0,4990 \\
3 \\
\end{tabular} & \begin{tabular}{|l}
0,4990 \\
9 \\
\end{tabular} & \begin{tabular}{|l}
0,4991 \\
5 \\
\end{tabular} & $\begin{array}{l}0,4992 \\
0 \\
\end{array}$ & $\begin{array}{l}0,4992 \\
1 \\
\end{array}$ \\
\hline & BEM & $\begin{array}{l}0,4969 \\
2 \\
\end{array}$ & \begin{tabular}{|l|}
0,4978 \\
1 \\
\end{tabular} & \begin{tabular}{|l}
0,4982 \\
0 \\
\end{tabular} & \begin{tabular}{|l|}
0,4984 \\
7 \\
\end{tabular} & \begin{tabular}{|l}
0,4986 \\
2 \\
\end{tabular} & \begin{tabular}{|l}
0,4987 \\
5 \\
\end{tabular} & \begin{tabular}{|l}
0,4988 \\
3 \\
\end{tabular} & \begin{tabular}{|l}
0,4989 \\
2 \\
\end{tabular} & \begin{tabular}{|l}
0,4989 \\
8 \\
\end{tabular} & $\begin{array}{l}0,4989 \\
9 \\
\end{array}$ & $\begin{array}{l}0,4990 \\
8 \\
\end{array}$ \\
\hline BRA & BEC & $\begin{array}{l}0,4962 \\
6 \\
\end{array}$ & $\begin{array}{l}0,4973 \\
3 \\
\end{array}$ & $\begin{array}{l}0,4978 \\
5 \\
\end{array}$ & $\begin{array}{l}, 4981 \\
2 \\
\end{array}$ & $\begin{array}{l}0,4983 \\
3 \\
\end{array}$ & \begin{tabular}{|l|}
0,4984 \\
6 \\
\end{tabular} & $\begin{array}{l}0,4985 \\
9 \\
\end{array}$ & \begin{tabular}{|l}
0,4986 \\
8 \\
\end{tabular} & \begin{tabular}{|l}
0,4987 \\
6 \\
\end{tabular} & $\begin{array}{l}0,4988 \\
2\end{array}$ & \begin{tabular}{|l|l}
0,4988 \\
7 \\
\end{tabular} \\
\hline & AMEX & $\begin{array}{l}0,4961 \\
6\end{array}$ & $\begin{array}{l}0,4973 \\
6 \\
\end{array}$ & $\begin{array}{l}0,4978 \\
3\end{array}$ & $\begin{array}{l}0,4981 \\
3\end{array}$ & $\begin{array}{l}0,4983 \\
2\end{array}$ & $\begin{array}{l}0,4984 \\
5\end{array}$ & $\begin{array}{l}0,4984 \\
4\end{array}$ & $\begin{array}{l}0,4986 \\
8\end{array}$ & $\begin{array}{l}0,4987 \\
3\end{array}$ & $\begin{array}{l}0,4988 \\
2\end{array}$ & $\begin{array}{l}0,4988 \\
4\end{array}$ \\
\hline & BMC & $\begin{array}{l}0,4845 \\
2\end{array}$ & \begin{tabular}{|l|}
0,4890 \\
1
\end{tabular} & $\begin{array}{l}0,4907 \\
2\end{array}$ & $\begin{array}{l}0,4923 \\
1\end{array}$ & $\begin{array}{l}0,4930 \\
0\end{array}$ & $\begin{array}{l}0,4936 \\
5\end{array}$ & $\begin{array}{l}0,4941 \\
5\end{array}$ & $\begin{array}{l}0,4943 \\
2\end{array}$ & $\begin{array}{l}0,4948 \\
3\end{array}$ & $\begin{array}{l}0,4950 \\
7\end{array}$ & $\begin{array}{l}0,4953 \\
6 \\
\end{array}$ \\
\hline & Banco Ibi & $\begin{array}{l}0,4975 \\
8\end{array}$ & $\begin{array}{l}\begin{array}{l}0,4983 \\
0\end{array} \\
\end{array}$ & $\begin{array}{l}0,4986 \\
0\end{array}$ & $\begin{array}{l}0,4987 \\
9\end{array}$ & $\begin{array}{l}0,4988 \\
8 \\
\end{array}$ & $\begin{array}{l}0,4990 \\
1\end{array}$ & $\begin{array}{l}0,4990 \\
9\end{array}$ & $\begin{array}{l}0,4991 \\
5\end{array}$ & $\begin{array}{l}0,4992 \\
0 \\
\end{array}$ & $\begin{array}{l}0,4992 \\
4\end{array}$ & $\begin{array}{l}0,4992 \\
8\end{array}$ \\
\hline & anco Fiat & $\begin{array}{l}0,4966 \\
9\end{array}$ & $\begin{array}{l}0,4976 \\
4 \\
\end{array}$ & $\begin{array}{l}0,4980 \\
4\end{array}$ & $\begin{array}{l}0,4983 \\
5\end{array}$ & $\begin{array}{l}0,4985 \\
4\end{array}$ & $\begin{array}{l}0,4986 \\
6 \\
\end{array}$ & $\begin{array}{l}0,4987 \\
5\end{array}$ & $\begin{array}{l}0,4988 \\
4\end{array}$ & \begin{tabular}{|l}
0,4988 \\
7
\end{tabular} & $\begin{array}{l}0,4989 \\
4\end{array}$ & $\begin{array}{l}0,4990 \\
1\end{array}$ \\
\hline & GF & $\begin{array}{l}0,4985 \\
7\end{array}$ & $\begin{array}{l}0,4990 \\
3 \\
\end{array}$ & $\begin{array}{l}0,4992 \\
0\end{array}$ & \begin{tabular}{|l}
0,4993 \\
2
\end{tabular} & $\begin{array}{l}0,4993 \\
6\end{array}$ & $\begin{array}{l}0,4994 \\
4\end{array}$ & $\begin{array}{l}0,4994 \\
8\end{array}$ & $\begin{array}{l}0,4995 \\
1\end{array}$ & \begin{tabular}{|l|}
0,4995 \\
4
\end{tabular} & $\begin{array}{l}0,4995 \\
6\end{array}$ & $\begin{array}{l}0,4995 \\
8\end{array}$ \\
\hline & BKB Brasil & $\begin{array}{l}0,4965 \\
9\end{array}$ & $\begin{array}{l}0,4975 \\
9\end{array}$ & $\begin{array}{l}0,4980 \\
0\end{array}$ & \begin{tabular}{|l}
0,4982 \\
6 \\
\end{tabular} & $\begin{array}{l}0,4984 \\
6\end{array}$ & $\begin{array}{l}0,4985 \\
9\end{array}$ & $\begin{array}{l}0,4987 \\
2\end{array}$ & $\begin{array}{l}0,4988 \\
0\end{array}$ & \begin{tabular}{|l}
0,4988 \\
6 \\
\end{tabular} & $\begin{array}{l}0,4989 \\
3\end{array}$ & $\begin{array}{l}0,4989 \\
7\end{array}$ \\
\hline Itaú & BKB U/CH & $\begin{array}{l}0,4959 \\
3\end{array}$ & \begin{tabular}{|l|}
0,4971 \\
1
\end{tabular} & $\begin{array}{l}0,4976 \\
5\end{array}$ & \begin{tabular}{|l}
0,4979 \\
6 \\
\end{tabular} & $\begin{array}{l}0,4981 \\
8\end{array}$ & $\begin{array}{l}0,4983 \\
4\end{array}$ & $\begin{array}{l}0,4984 \\
6\end{array}$ & $\begin{array}{l}0,4985 \\
6\end{array}$ & \begin{tabular}{|l|l}
0,4986 \\
4
\end{tabular} & $\begin{array}{l}0,4987 \\
1\end{array}$ & $\begin{array}{l}0,4987 \\
6\end{array}$ \\
\hline & Unibanco & $\begin{array}{l}0,4936 \\
0\end{array}$ & \begin{tabular}{l|}
0,4950 \\
8
\end{tabular} & \begin{tabular}{|l|}
0,4963 \\
8
\end{tabular} & \begin{tabular}{|l|}
0,4967 \\
7
\end{tabular} & \begin{tabular}{l|l|}
0,4972 \\
4
\end{tabular} & \begin{tabular}{|l|l}
0,4974 \\
4
\end{tabular} & $\begin{array}{l}0,4975 \\
9\end{array}$ & $\begin{array}{l}0,4977 \\
6\end{array}$ & \begin{tabular}{|l|}
0,4979 \\
1
\end{tabular} & $\begin{array}{l}0,4980 \\
3\end{array}$ & $\begin{array}{l}0,4981 \\
2\end{array}$ \\
\hline & BMG & $\begin{array}{l}0,4965 \\
4\end{array}$ & $\begin{array}{l}0,4975 \\
2\end{array}$ & $\begin{array}{l}0,4979 \\
7\end{array}$ & $\begin{array}{l}0,4982 \\
8\end{array}$ & $\begin{array}{l}0,4984 \\
4 \\
\end{array}$ & $\begin{array}{l}0,4985 \\
2\end{array}$ & \begin{tabular}{|l|}
0,4987 \\
1
\end{tabular} & \begin{tabular}{|l|}
0,4987 \\
9
\end{tabular} & $\begin{array}{l}0,4988 \\
3\end{array}$ & $\begin{array}{l}0,4989 \\
0\end{array}$ & \begin{tabular}{l|}
0,4989 \\
6 \\
\end{tabular} \\
\hline & Credicard & $\begin{array}{l}0,4973 \\
3\end{array}$ & $\begin{array}{l}0,4981 \\
5\end{array}$ & $\begin{array}{l}0,4984 \\
9\end{array}$ & $\begin{array}{l}0,4986 \\
9\end{array}$ & $\begin{array}{l}0,4988 \\
1\end{array}$ & $\begin{array}{l}0,4989 \\
3\end{array}$ & $\begin{array}{l}0,4990 \\
1\end{array}$ & \begin{tabular}{|l}
0,4990 \\
7
\end{tabular} & \begin{tabular}{|l|}
0,4991 \\
2
\end{tabular} & $\begin{array}{l}0,4991 \\
6\end{array}$ & $\begin{array}{l}0,4992 \\
0 \\
\end{array}$ \\
\hline
\end{tabular}

\section{Resultados em Longo Prazo - EVA® - Economic Value Added}

A elevação na concentração bancária no Brasil promovida por fusões e aquisições, entre 2000-2003, foi decorrência de um período em que os bancos buscavam por novas fontes de receitas e escala, principalmente em face da redução de ganhos devido à tendência e queda nas taxas de juros (ALENCAR \& MARTINS, 2008). Também, no primeiro semestre de 2003, a economia brasileira sofreu ajustes na política monetária e fiscal, com objetivo de redução da inflação e da volatilidade das taxas de câmbio, como consequência, melhoria da percepção do risco-país. O ambiente macroeconômico em recuperação contribuiu para com menor agregação de valor às instituições financeiras, mas, por outro lado, se beneficiaram da redução de risco propiciada pela diversificação dos negócios decorrentes da consolidação do segmento de indústria. Neste período, é observado, que as principais instituições financeiras participantes de transações em F\&A's não agregaram valor ao acionista (Itaú: Banco Fiat; Bradesco: Banco Bilbao Vizcaya e Banco Zogbi). 
A partir de 2003, observa-se que os bancos privados modificaram seus portfólios de ativos, expandindo de forma ativa o crédito para os agentes privados. Esta mudança de atitude está relacionada a alteração no mix de atividades mais rentáveis para os bancos, com esta última ganhando cada vez maior importância ao longo do ciclo. Ao longo de 2004, a economia brasileira registrou recuperação do nível de atividade decorrente das exportações e do crescimento nos demais setores de produção. Também, foi observado a expansão do crédito, principalmente para pessoas físicas, em decorrência do aumento da massa salarial que recuperou a demanda interna e melhoria do PIB, em cerca de 4,5\%. Com isto, a estratégia adotada por bancos privados foi da aquisição de bancos do segmento de crédito massificado (Bradesco: Banco Zobgi e o Banco do Estado do Maranhão). Entretanto com objetivos diferenciados, uns buscavam a economias em escala para competividade, outros, a manutenção da participação de mercado já conquistada.

A expansão do crédito, às pessoas físicas, foi vista como um potencial de ganho para as instituições financeiras, pois as taxas de juros praticadas neste segmento físicas são superiores às outras linhas de crédito, portanto, um produto rentável, frente recuperação do emprego. crédito consignado representou uma inovação financeira, produto de boa comercialização, rentabilidade. A contínua expansão das operações de financiamento direto ao consumidor e do crédito consignado, entre 2005-2007, fez com que os conglomerados financeiros estabelecessem estratégias diferenciadas para à busca do ganho em escala. Para isto, estabeleceram acordos operacionais com redes de lojas de varejo para o financiamento de suas vendas. Este nicho é extremamente competitivo e requer escala. Por isto, é observado neste triênio, as aquisições do Amex e BMC pelo Bradesco e Bank Boston pelo Itaú.

O ano de 2008 foi notadamente marcado pela crise internacional que culminou com a falência do banco de investimentos, norte-americano, Lehmann Brothers, gerando retração da liquidez e das linhas de crédito, no mercado financeiro internacional. No Brasil, um dos efeitos da crise, foi da redução das linhas internacionais de crédito. Neste período, os bancos públicos tiveram preponderância na concessão de crédito, para o financiamento das decisões de investimento e produção das empresas. Em oposição a este movimento, os bancos privados, avessos aos riscos e as incertezas, restringiram as linhas de crédito.

As crises bancárias, choques setoriais, em sua grande maioria, é seguida por ondas de fusões e aquisições que elevam a concentração do sistema financeiro (Banco Brasil: Besc, Nossa Caixa e BEP e Itaú: Unibanco). Este movimento diversifica os riscos das operações das instituições financeiras, tornando menos vulneráveis aos eventos.

Ao longo de dez anos (2003-2013), as instituições financeiras realizaram sucessivas fusões e aquisições para obter economia em escala e escopo face à demanda interna, mas associada a capacidade de integração dos negócios e da manutenção de sua eficiência operacional. Os investimentos em fusões e aquisições, realizados entre 2003-2010, pelas instituições financeiras demonstraram, em sua maioria, a agregação de valor ao acionista, 
conforme a evolução do $E V A^{\circledR}$, no quadro 5 , demonstra, em sua maioria, agregação de valor ao acionista.

Quadro 5: 2003-2013 - Resumo da Evolução do $E V A^{\circledR} P R$.

\begin{tabular}{|l|l|l|l|l|l|l|l|l|l|l|l|}
\hline EVA $\Theta$ & $\mathbf{2 0 0 3}$ & $\mathbf{2 0 0 4}$ & $\mathbf{2 0 0 5}$ & $\mathbf{2 0 0 6}$ & $\mathbf{2 0 0 7}$ & $\mathbf{2 0 0 8}$ & $\mathbf{2 0 0 9}$ & $\mathbf{2 0 1 0}$ & $\mathbf{2 0 1 1}$ & $\mathbf{2 0 1 2}$ & $\mathbf{2 0 1 3}$ \\
\hline BB & 1.588 & -204 & -521 & 1.430 & 933 & 3.317 & 4.313 & 4.682 & 3.227 & 2.205 & 1.603 \\
\hline Itaú & -853 & 566 & 1.328 & -291 & 4.107 & 622 & 5.869 & 4.831 & 3.895 & 3.057 & 6.270 \\
\hline BRA & -1.943 & -306 & 656 & -203 & 3.110 & 1.743 & 2.490 & 4.571 & 2.815 & 3.162 & 4.638 \\
\hline
\end{tabular}

Para fins de contribuição com os resultados identificados pela métrica do $E V A^{\circledR}$, o quadro 6 indica a evolução do Índice de Eficiência Operacional (IEO), registrando o êxito dos esforços simultâneos de elevação das receitas líquidas e da redução de custos, comparando-se as despesas administrativas (inclusive pessoal) com o resultado operacional (resultado da intermediação financeira ajustado). O triênio 2003 a 2005 indica que a integração dos investimentos realizados em fusões e aquisições, principalmente pelo Banco Itaú e Bradesco e da busca por eficiência operacional em bancos públicos.

A partir de 2009, os índices de eficiência indicam que os esforços para contenção de custos, inclusive dos benefícios das F\&A's, não tem sido suficiente para a manutenção da rentabilidade das instituições, muito embora, ainda haja agregação de valor para os acionistas do Banco do Brasil, Bradesco, Itaú-Unibanco. Os resultados de IEO corroboram o entendimento de que bancos que já possuem escala e realizam as $\mathrm{F} \& A$ 's, não apresenta redução significativa das despesas administrativas, mas efetivamente, necessariamente, buscam pela diversificação dos serviços para a manutenção das taxas de crescimento.

As ondas massivas de F\&A's e alterações na taxa básica de juros SELIC, pressionam os bancos brasileiros para a melhoria de eficiência operacional e da busca por novos serviços, mas é importante ressaltar que os índices de eficiência registrados desde 2003, tiveram redução média de 10 p.p., em um horizonte de 10 anos, apontando como novo padrão, eventual, o IEO atingido pelo Bradesco, de $42,10 \%$.

Quadro 6: Evolução do Índice de Eficiência Operacional.

\begin{tabular}{|c|c|c|c|c|c|c|c|c|c|c|c|}
\hline IEO. & 2003 & 2004 & 2005 & 2006 & 2007 & 2008 & 2009 & 2010 & 2011 & 2012 & 2013 \\
\hline B & $56,30 \%$ & $54,20 \%$ & $48,10 \%$ & $47,50 \%$ & $51,40 \%$ & $45,60 \%$ & $40,70 \%$ & $42,60 \%$ & $42,10 \%$ & $43,20 \%$ & $46,60 \%$ \\
\hline Itaú & $58,50 \%$ & $58,60 \%$ & $53,20 \%$ & $50,50 \%$ & $49,80 \%$ & $48,70 \%$ & $47,20 \%$ & $48,80 \%$ & $47,00 \%$ & $46,60 \%$ & $48,70 \%$ \\
\hline BRA & $56,59 \%$ & $55,47 \%$ & $44,80 \%$ & $42,13 \%$ & $43,33 \%$ & $43,70 \%$ & $41,02 \%$ & $42,70 \%$ & $43,00 \%$ & $41,50 \%$ & $42,10 \%$ \\
\hline
\end{tabular}

O quadro 7 demonstra a evolução do patrimônio de referência do banco do Brasil, ItaúUnibanco e Bradesco em de acordo com as regras da Basiléia vigentes a cada ano. O patrimônio Referência é composto pelo capital nível I: PL e ajustes; e II: dívidas subordinadas e instrumentos híbridos de capital. Entre os ajustes que impactam o patrimônio de referência, há o ágio, ativo diferido, créditos tributários. Em 2008-2009, o excedente da provisão com perdas para com operações de crédito decorrente das novas regras de constituição e específicos instrumentos híbridos de capital e dívida foram adicionados na composição do capital nível I. Este último em especial, foi instrumento amplamente utilizado pelo BB na composição de seu capital regulatório. 
As fontes secundárias de capital, em especial as dívidas subordinadas e instrumentos híbridos de capital e dívida, embora, hoje com teto máximo, compõem em média 30,29\% do capital do BB, $21,61 \%$ do Itaú e $24,58 \%$ do Bradesco registrados entre 2003 a 2013 . A utilização de outras formas jurídicas de capital, para a composição do patrimônio de referência, de acordo com as regras propostas pela Basiléia e o Conselho Monetário Nacional, de certa forma, abstém da integralização de capital próprio para a manutenção dos níveis operacionais de cada banco.

Quadro 7: Evolução do Patrimônio de Referência.

\begin{tabular}{|l|l|l|l|l|l|l|l|l|l|l|l|}
\multicolumn{1}{l|}{ R\$ bilhões. } & $\mathbf{2 0 0 3}$ & $\mathbf{2 0 0 4}$ & $\mathbf{2 0 0 5}$ & $\mathbf{2 0 0 6}$ & $\mathbf{2 0 0 7}$ & $\mathbf{2 0 0 8}$ & $\mathbf{2 0 0 9}$ & $\mathbf{2 0 1 0}$ & $\mathbf{2 0 1 1}$ & $\mathbf{2 0 1 2}$ & $\mathbf{2 0 1 3}$ \\
\hline BB & 17.162 & 20.050 & 24.639 & 30.755 & 34.900 & 44.118 & 59.099 & 68.257 & 82.153 & 109.285 & 118.234 \\
\hline Itaú & 17.317 & 19.937 & 20.681 & 30.664 & 36.936 & 66.766 & 68.432 & 78.671 & 92.560 & 119.945 & 125.143 \\
\hline BRA & 18.372 & 20.843 & 25.605 & 35.109 & 42.111 & 47.737 & 55.464 & 55.968 & 71.127 & 96.625 & 95.804 \\
\hline
\end{tabular}

A evolução dos APR's registrada entre 2003-2013, conforme quadro 8, demonstra que o $\mathrm{BB}$ aumentou em 6,67 vezes para um lucro líquido de $\mathrm{R} \$ 11.289$ milhões, Itaú-Unibanco em 9,42 para um lucro de $R \$ 16.522$ e o Bradesco em 6,23 para um lucro líquido de $R \$ 12.486$. Para estes vetores, observa-se que o Banco Bradesco teve eficiência significativa em comparação com o BB. Por outro lado, Itaú-Unibanco, demonstra que a proporcionalidade para APR's em torno de $\mathrm{R} \$ 750-800$ milhões é de lucro líquido em torno de $\mathrm{R} \$ 17$ milhões, muito embora, cabe ressaltar que a instituição passou por dois exercícios com resultados não proporcionais aos APR's, IEO acima de seus concorrentes, principalmente em face ao processo de reorganização pós fusão e outros eventos: elevação da taxa de juros, inflação e consequentemente da inadimplência.

Quadro 8: Evolução dos Ativos Ponderados ao Risco (APR's).

\begin{tabular}{|l|l|l|l|l|l|l|l|l|l|l|l|}
\multicolumn{1}{|c|}{ R\$ bilhões } & $\mathbf{2 0 0 3}$ & $\mathbf{2 0 0 4}$ & $\mathbf{2 0 0 5}$ & $\mathbf{2 0 0 6}$ & $\mathbf{2 0 0 7}$ & $\mathbf{2 0 0 8}$ & $\mathbf{2 0 0 9}$ & $\mathbf{2 0 1 0}$ & $\mathbf{2 0 1 1}$ & $\mathbf{2 0 1 2}$ & $\mathbf{2 0 1 3}$ \\
\hline BB & 122.044 & 128.488 & 140.968 & 172.986 & 215.851 & 283.715 & 420.936 & 463.706 & 568.540 & 722.141 & 813.623 \\
\hline Itaú & 80.171 & 92.301 & 115.838 & 169.414 & 197.524 & 413.813 & 402.541 & 497.468 & 579.338 & 661.796 & 755.441 \\
\hline BRA & 92.569 & 111.182 & 148.392 & 187.173 & 269.136 & 282.008 & 312.488 & 371.602 & 473.373 & 597.519 & 576.777 \\
\hline
\end{tabular}

A evolução dos lucros dos bancos brasileiros, demonstrados no quadro 9, corroboram o entendimento na teoria de que quanto maior o risco maior o retorno, no entanto, não julgamos a qualidade dos ativos e a política de alavancagem de cada um, mas é importante correlacionar que os resultados indicados em 2013 somente serão registrados se houver APR's ente R\$570 a R\$ 820 milhões que não seriam obtidos com a manutenção do status quo de suas operações associadas ao crescimento orgânico. O BB atingiu o crescimento de $374 \%, 424 \%$ para o Itaú e $441 \%$ para o Bradesco.

Quadro 9: Evolução do Lucro Líquido (LL).

\begin{tabular}{|l|l|l|l|l|l|l|l|l|l|l|l|} 
\$ bilhões. & $\mathbf{2 0 0 3}$ & $\mathbf{2 0 0 4}$ & $\mathbf{2 0 0 5}$ & $\mathbf{2 0 0 6}$ & $\mathbf{2 0 0 7}$ & $\mathbf{2 0 0 8}$ & $\mathbf{2 0 0 9}$ & $\mathbf{2 0 1 0}$ & $\mathbf{2 0 1 1}$ & $\mathbf{2 0 1 2}$ & $\mathbf{2 0 1 3}$ \\
\hline BB & 2.381 & 3.024 & 4.154 & 6.044 & 5.058 & 8.803 & 10.148 & 11.330 & 12.737 & 11.438 & 11.289 \\
\hline Itaú & 3.152 & 3.776 & 5.251 & 4.309 & 8.474 & 8.924 & 12.626 & 12.494 & 14.610 & 13.191 & 16.522 \\
\hline BRA & 2.306 & 3.060 & 5.514 & 5.054 & 8.010 & 7.620 & 8.012 & 10.052 & 11.089 & 11.352 & 12.486 \\
\hline
\end{tabular}




\section{CONCLUSÕES}

O sistema bancário no Brasil é o maior e mais complexo da América Latina. Assim como em outras partes do mundo, o setor bancário brasileiro vivenciou um processo de transformação significativo e radical. As características em comum deste processo, no Brasil e em outros países, incluem o aumento na competição local da indústria, bem como da entrada de capitais de bancos estrangeiros e de outros negócios considerados transnacionais, propiciando ondas de fusão e aquisição. O mercado financeiro se tornou globalizado, com fluxos de capitais voláteis e capazes de causar estragos no sistema financeiro local-global. Período de diversas inovações tecnológicas e de produtos financeiros, como também do estabelecimento de práticas regulatórias do setor.

O setor bancário, no Brasil, tem sido fortemente influenciado pelas mudanças da política local macroeconômica, especialmente, em 1994 pela transição de uma economia de altas taxas inflacionárias para um ambiente de preços controlados e inflação reduzida. Durante, muitos anos da dependência das inflacionárias, os participantes do sistema financeiro nacional tiveram de se reestruturar e buscar por um novo mix de produtos e pela constante eficiência operacional de suas atividades. A expansão do crédito foi a alternativa utilizada pelos bancos brasileiros como forma de compensação das perdas inflacionárias. Contudo, as concessões não foram seguidas de boas políticas de crédito, gerando um cenário de instabilidade e perdas.

A insolvência iminente de grandes bancos privados fez com que o governo federal e o Banco Central colocassem em prática um plano de resgate e recuperação do sistema financeiro Nacional através dos programas PROER e PROES, como tentativa de não estrangulamento e bancarrota do setor, consequentemente da economia do país. Desde então, é observado uma grande onda de fusões e aquisições, onde os bancos brasileiros se transformaram em conglomerados financeiros, diversificados e com atuação geográfica expandida.

As F\&A's iniciadas com ciclo de estabilidade monetária teve suas motivações galgadas na necessidade redução dos riscos de insolvência. Tempos depois, a flexibilização das regras para entrada de capitais estrangeiros, no setor bancário, provocou uma nova onda de F\&A's dos principais bancos privados nacionais, como uma vigorosa reação aos entrantes. Findo este período de euforia de entrantes estrangeiros no sistema financeiro nacional, muitos, decidiram pela inversão de seus investimentos locais por participações em grandes bancos privados nacionais.

Embora, as motivações tenham uma gama de justificativas, envolvendo características do setor, país, a fundamentação econômica para F\&A's, em instituições financeiras não diverge de outros negócios. A maximização do lucro do acionista através da criação de valor é a justificativa de grande parte dos gestores por tal decisão de investimento.

De forma notória, instituições financeiras buscam economias de escala, escopo, eficiência, produtividade, poder de mercado e melhoria da gestão, como corroborados por Brewer et al. (2000), Penas e Unal (2004) Henock (2004). Mas, também, é importante ressaltar que o fator de 
sucesso destas transações é o processo de integração dos negócios a ser realizada pela administração, portanto, da mensuração efetiva das sinergias identificadas e da capacitação suficiente da gerência em gerir tais oportunidades. Por isto e entre tantas outras motivações delineadas na pesquisa, as transações F\&A's despertam no meio acadêmico a constante pesquisa, mas também, porque os resultados observados não revelam uma direção única sobre geração de valor em face destas políticas de investimento, mas evidencia, em grande parte, a destruição de valor e de desempenhos econômico financeiros não suficientes para tal monta de investimento.

A presente pesquisa evidenciou que as decisões de investimento em aquisições e fusões dos quatro principais bancos brasileiros: Banco do Brasil, Bradesco, Itaú-Unibanco tiveram, em sua maioria, resultados agregadores de valor ao seu acionista, em um horizonte de longo prazo, medidos pelo $E V A^{\circledR}$, entretanto, em curto prazo, através de estudos de eventos, a variância da precificação das ações entorno da divulgação, de cada banco, não teve significância estatística. Resultado corrobora que F\&A's são decisões de investimento cujos efeitos serão percebidos em longo prazo, aliados a manutenção de um cenário macroeconômico que foi base da motivação de seus gestores.

Fica evidente que a globalização, volatilidade dos fluxos de capitais, instabilidade nos fundamentos macroeconômicos contribuem para com choques na economia e certamente, os participantes do sistema financeiro nacional tendem a tomar medidas de proteção e da manutenção da liquidez dos mercados, propiciando ondas de F\&A's, dada a importância do setor na economia brasileira e de qualquer outro país.

\section{REFERENCIAS}

ALENCAR, L. S.; MARTINS, B. S.. Relatório de Economia Bancária e Crédito, Estudos Selecionados. Banco Central do Brasil, 2008.

AMEL, D.; BARNES, C.; PANETTA, F.; SALLEO, C.. Consolidation and efficiency in the financial sector: a review of the international evidence. Journal of Banking and Finance, n.28, p.2493-2519, 2004.

ASSAF NETO, A.. Finanças Corporativas e Valor. 6 ed. São Paulo: Atlas, 2012.

BASTOS, N. T.. Avaliação de Desempenho de Bancos Brasileiros baseada em Criação de Valor Econômico. Revista de Administração da USP, v.34, n.3, p.68-73, 1999.

BECHER, D. A.; CAMPBELL, T. L.. Interstate banking deregulation and the changing nature of bank mergers. Journal of Financial Research, n.28, p.1-20, 2005.

BELL, L. W. W.. Economic Profit: An Old Concept Gains New Significance. Journal of Business Strategy, n.19, v.5, p.13-15, 1998.

BERGER, A. N.; DEMSETZ, R. S.; STRAHAN, P. E.. The consolidation of the financial services industry: causes, consequences, and implications for the future. Journal of Banking and Finance, n.23, p.135-194, 1999.

BEGER, A. N.. The economic effects of technological progress: evidence from the banking industry. Journal of Money, n.35, p.141-176, 2003.

BIDDLE, G. C.; BOWEN, G. S.; WALLACE, J. S.. Does $E V A^{\circledR}$ beat Earnings? Evidence on Associations with Stock Returns and Firm Values. Journal of Accounting and Economics, v.24, n.3, p.301-336, 1997. 
BREWER, E.; JACKSON, W. E.; JAGTIANI, J.; NGUYEN, T.. The price of bank mergers in the 1990s. Chicago: Federal Reserve Bank Chicago Economic Perspective, 2000.

BRITO, G. A. S.; BATISTELA, F. D.; FAMÁ, R.. Fusões e aquisições no setor bancário: avaliação empírica do efeito sobre o valor das ações. Revista de Administração, São Paulo, v.40, n.4, p.353-360, 2005.

CAMPBELL, J. Y.; LO, A. W.; MACKINLEY, A. C.. The econometrics of financial markets. 2 ed. New Jersey: Princeton University Press, 1997.

DANIEL, K. D.; TITAMAN, S.. Market efficiency in an irrational world. Financial Analysts' Journal 55, 1999. DOI: http://dx.doi.org/10.2469/faj.v55.n6.2312

DELONG, G. L.. Stockholder gains from focusing versus diversifying bank mergers. Journal of Financial Economics, n.59, p.221-252, 2001.

DELONG, G.L.; DEYOUNG, R.. Learning by observing: Information spillovers in the execution and valuation of commercial bank M\&A's. Journal of Finance, n.62, p.181-216, 2005.

DYMSKI, G. A.. The bank merger wave: the economic causes and social consequences of financial consolidation. New York: ME Sharpe, 1999.

FAMA, E.. The Behavior of Stock Prices. Journal of Business 47, p.244-280, 1965,

HENOCK, L.. The cost of using bank mergers as defensive mechanisms against takeover threats. Journal of Business, n.77, p.295-310, 2004.

HUMPHREY, D. B.; WILLESSON, M.; BERGENDAHL, G.; LINDBLOM, T.. Benefits from a changing payment technology in European banking. Journal of Banking and Finance, n.30, p.1631-1652, 2006.

JENSEN, M.; RUBACK, R..The market for corporate control: the scientific evidence. Journal of Financial Economics, v. 11, p. 5-50, 1983,

JOKIPII, T.; MILNE, A.. Bank capital buffer and risk adjustment decisions. Journal of Financial Stability, 7, p.165-178, 2011.

JONES, K.D.; CRITCHFIELD, T.. Consolidation in the U.S. banking industry: is the 'long, strange trip' about to end? FDIC. Banking Review, n.17, p.31-61, 2005.

OLSON, G. T.; PAGANO, M. S.. A new application of sustainable growth: a multi-dimensional framework for evaluating the long run performance of bank mergers. Journal of Business, Finance and Accounting, n.32, p.1995-2036, 2005,

PENAS, M. F.; UNAL, H.. Gains in bank mergers: evidence from the bond market. Journal of Financial Economics, n.74, p.149-179, 2004.

PAULA, L. F.; OREIRO, J. L.; BASÍLIO, F. A. C.. Estrutura do setor bancário e o ciclo recente de expansão do crédito: O papel dos bancos públicos federais. Nova Economia, v.23, n.3, 2013.

ROSSETTI, J. P.. Fusões e aquisições no Brasil: as razões e os impactos. São Paulo: Atlas, 2001.

SAUNDERS, A.. Administração de instituições financeiras. São Paulo: Atlas, 2000.

SANTOMERO, A.. Banks mergers: What's a policemaker to do? Journal of Finance, v.23, p.637-643, 1999.

STERN, J. M.; STEWART, G. B.; CHEW, D. H.. The EVA Financial Management System. Journal of Applied Corporate Finance, v.8, n.2, p.32-46, 1995.

SOLOMONS, D.. Divisional Performance: Measurement and Control. Homewood: Irwin, 1965.

TVERSKY, A.; KAHNEMAN, D.. The framing of decisions and the psychology of choice. Science 211, p.453-58, 1981. 